\title{
AN ANALYSIS OF THE DEVELOPMENT OF THE FIRE LOSSES IN THE NORTHERN COUNTRIES AFTER THE SECOND WORLD WAR
}

\author{
Hans Andersson
}

Sweden

In several different countries there has lately been a very unfavourable development as far as fire losses are concerned. There have been many and very bad big fires which have especially affected industry and trade. The facts which can be considered to have caused this development are well-known. Bigger and bigger and more concentrated units of production, business enterprises, and storing form an accumulation of values which in itself implies increasing risks. On account of production-technical and businesseconomical conditions it has not always been possible to divide the buildings into sections desirable from a fire service point of view. The new production methods have sometimes caused new fire risks.

The Northern Central Office for Fire Insurance Statistics from Mutual Companies (CNÖB) has made an investigation in order to see to what extent the international trend towards increasing fire losses has any equivalence in the Northern countries (Denmark, Finland, Norway, and Sweden). I.a. there was made a graphical representation of how the observed rate of net risk premium of the portfolio has developed during the period I946-I966, the result of which may be seen from fig. I. No increasing trend can be observed from this. After having been decreasing during the immediate postwar time, the observed rate of net risk premium has been fairly constant from the beginning of the fifties, perhaps even somewhat decreasing except during the later years. The conclusion is that in so far facts as mentioned above have influenced the development of claims of the portfolios or parts of these in a deteriorating way, there must in that case have been circumstances which have worked as neutralizers. It is as a matter of fact rather easy to find such circumstances. The ratio of stone buildings in relation to wooden 
buildings has increased which must have reduced the observed rate of net risk premium, and the measures taken in the Northern countries in order to reconstruct and adjust the city centres have surely been of very great importance. The improved fire service should also be mentioned.
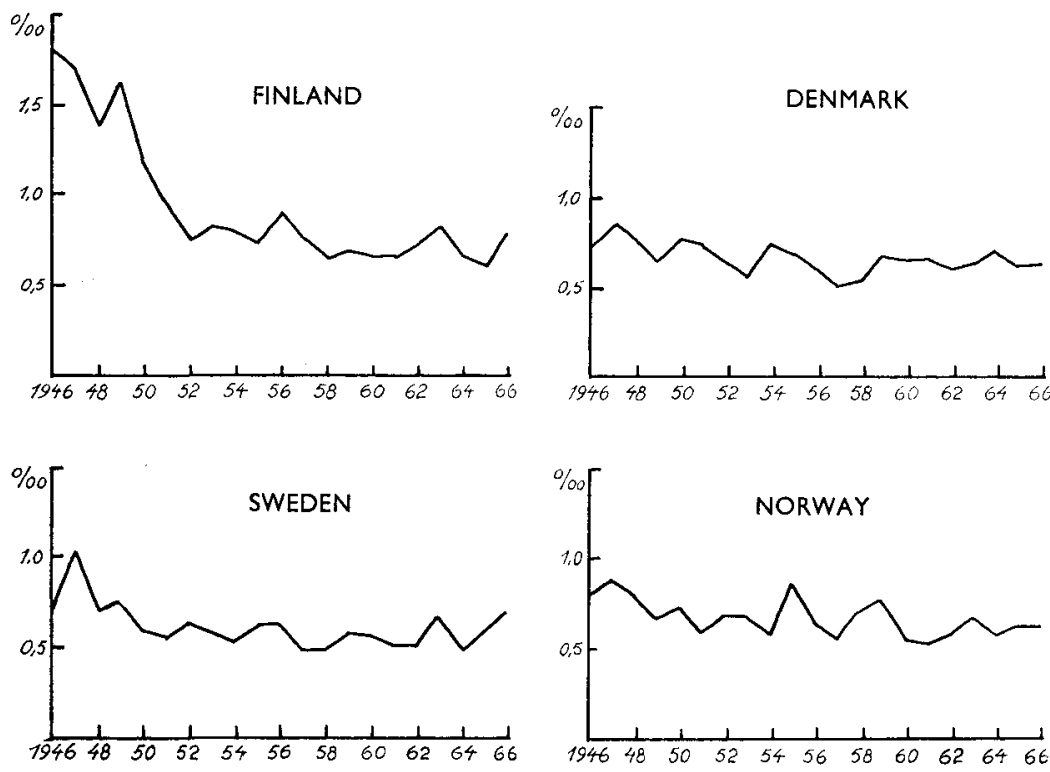

Fig. I.

CNÖB has also found that at the same time as the observed rate of net risk premium has been remarkably constant, the portion of large claims of the entire loss experience has somewhat increased. It is easy to see that such a development was to be expected if the hypothesis related above about the importance of the different facts regarding the development of claims were correct. It must, however, be added that the observed trend has not been particularly strong.

Furthermore, CNÖB has investigated the number and extent of the big fires. The year I95I, when circumstances may be considered to have been fairly normalized after the war, was this time chosen as basis and in order to neutralize the influence of inflation all compensation amounts were converted into the values of the year I95I. 
A large claim was defined as a claim with a compensation amount of Sw. Kr 250,000 or about $£ \mathrm{I} 7,500$ (the amounts as per the value of the year I95 I). The value conversion was for the sake of simplicity made so that the different countries' index series for building costs of residential properties were used as basis. It would have been more correct to have divided the large claims into categories of risks and thereafter, for every category of risk, to use some index more appropriate for it. The method used is legitimated by the fact that the difference between the various index series has not been of any great importance.
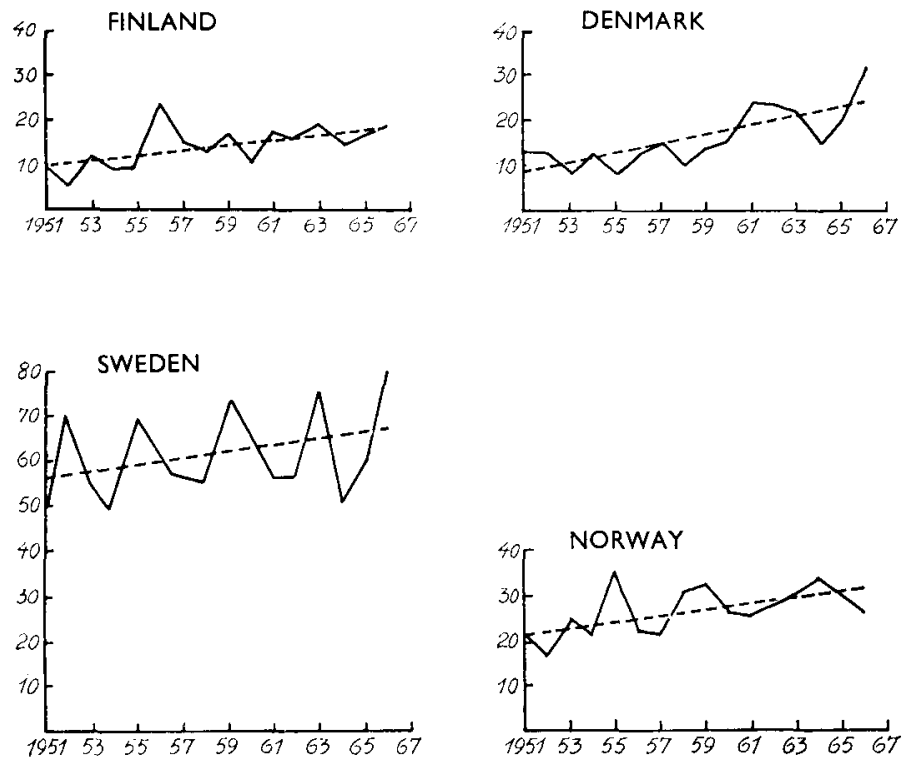

Fig. 2.

The variation in the number of big fires I95I-I966 can be seen from fig. 2, where also straight lines of trend are shown. The number of fires has gradually increased, but seen against the great increase of the insurance portfolio during the same time the development is not particularly remarkable.

CNÖB has also tried to study the distribution of the large claims. On account of the small quantity occurring each year it became necessary to put together the material into two periods, I95I-I958 
and I959-I966, whereafter the distribution of large claims for these two periods were compared with each other. The comparison is illustrated graphically in fig. 3 , where the compensation amount can be read from the $X$-axis, while on the $Y$-axis the number of large claims $\geqq$ the compensation amounts $X$ is shown. The scales are logarithmic.

FINLAND

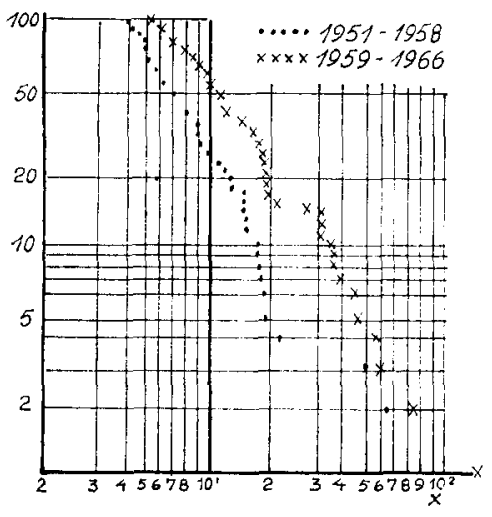

SWEDEN

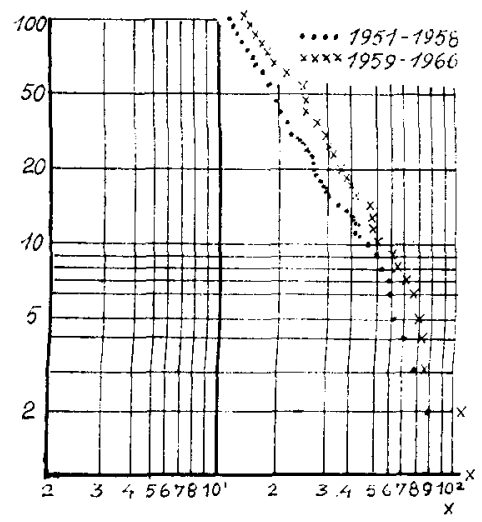

DENMARK

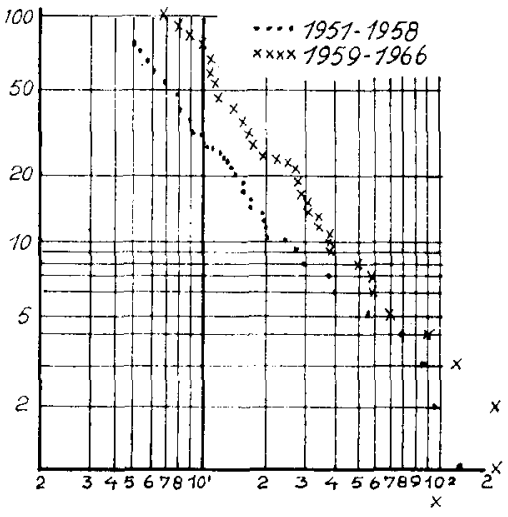

NORWAY

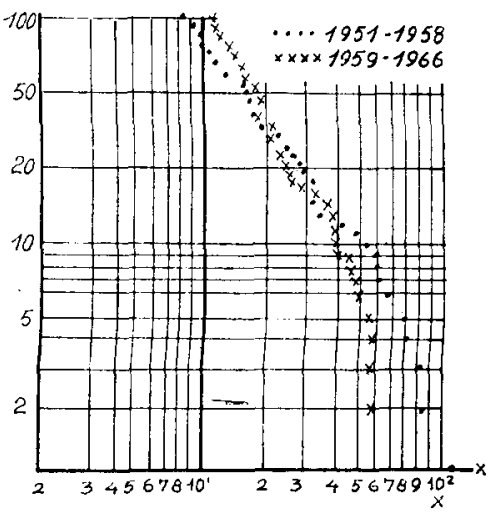

Fig. 3 .

One can see that there are certain differences between the two periods and that these are somewhat different in the four countries. To get a better view of the signification of this difference one needs 
an analytical representation. A simple such a one is Pareto's distribution which corresponds to straight lines in figures of the same type as has been used in fig. 3. The acquired curves are not rectilinear, but $\mathrm{CNOB}$ has not considered the deviations big enough to prevent a use of Pareto's distribution as an approximation permissible in this connection. If the limit of large claims $=X_{1}$ we have the distribution function

$$
F(X)=\mathrm{I}-\left(\frac{X}{X_{0}}\right)^{-\infty} \quad \text { for } X \geqq X_{0}
$$

We indicate the parameter in such a way that $\alpha_{1}$ corresponds to the first and $\alpha_{2}$ to the second period. If the corresponding mean values are termed $m_{1}$ and $m_{2}$ we get

$$
\frac{m_{2}}{m_{1}}=\frac{\alpha_{2}\left(\alpha_{1}-\mathrm{I}\right)}{\alpha_{1}\left(\alpha_{2}-\mathrm{I}\right)}
$$

independent of the $X_{0}$ identical for both periods.

From the material given the $\alpha$-values have been estimated according to the maximum-likelihood method whereafter $m_{2} / m_{1}$ has been estimated by inserting the values obtained in this way.

RESULT

\begin{tabular}{lccc}
\hline & $\alpha_{1}$ & $\alpha_{2}$ & $m_{2} / m_{1}$ \\
\hline I)enmark & $\mathrm{I}, 39$ & $\mathrm{I}, 26$ & $\mathrm{I}, 4$ \\
Finland & $\mathrm{I}, 76$ & $\mathrm{I}, 25$ & 2,2 \\
Norwaly & $\mathrm{I}, 32$ & $\mathrm{I}, 37$ & 0,9 \\
Swedien & $\mathrm{I}, 49$ & $\mathrm{I}, 38$ & $\mathrm{I}, 2$ \\
\hline
\end{tabular}

One can see that after having made an inflationary correction the average large claim has not increased for Norway between the periods I95I-I958 and I959-I966. For Finland there is an increase, but for this country the value of the first period was rather low. For Denmark and Sweden increasements are registered, but smaller than for Finland.

The $\alpha$-values obtained indicate furthermore that the difference in distribution of large claims between the four countries shows a tendency to being levelled. 
It has already been emphasized that the observed material concerning large claims is small and that Pareto's distribution can give only a rough approximation. The result must therefore not be pressed, but one can, however, reach the conclusion that the international trend towards a pronounced increase in the number of large claims has had less effect on the northern statistics for the period investigated than was to be expected. 